\title{
Beliefs about sharing illness experiences in chronic fatigue syndrome: the role of interpersonal trust and personality
}

\begin{abstract}
BACKGROUND
Disclosure of illness and illness experiences can be complicated for patients diagnosed with chronic fatigue syndrome due to the stigma associated with the illness. In this study, we evaluate the psychometric properties of the Beliefs about Sharing Illness Experiences (BASIE) scale in chronic fatigue patients. In addition, we investigate whether interpersonal trust and personality characteristics predict self-disclosure in chronic fatigue patients.
\end{abstract}

\section{PARTICIPANTS AND PROCEDURE}

The research was carried out in Rasht City, Iran. Participants were patients with chronic fatigue syndrome $(N=280)$ who were referred to Rasht pain management clinics in 2019. The psychometric properties of the BASIE scale were evaluated using content validity (CVI and CVR), exploratory factor analysis (EFA), confirmatory factor analysis (CFA), and Cronbach's $\alpha$. In addition, Pearson's correlation and multiple regression were used to test the roles of interpersonal trust and personality in predicting willingness to share illness experiences in chronic fatigue syndrome patients.
RESULTS

A CVI of .91 and CVR of .92 showed strong content validly for the BASIE scale. EFA and CFA supported a twofactor structure of the instrument. The Cronbach's $\alpha$ of .94 confirmed strong reliability. Multiple regression analysis revealed that positive beliefs about sharing illness experiences were predicted by higher interpersonal trust, higher extraversion, and lower neuroticism.

\section{CONCLUSIONS}

The BASIE scale appears to be an appropriate tool for measuring chronic fatigue syndrome patients' beliefs about sharing illness experiences. Also, interpersonal trust, extraversion, and neuroticism play important roles in sharing illness experiences. These findings may be helpful in the management of chronic fatigue syndrome and other stigmatized illnesses.

\section{KEY WORDS}

illness experience; interpersonal trust; personality; chronic fatigue syndrome; measurement

ORGANIZATION - 1: University of Tehran, Tehran, Iran · 2: University of Guilan, Rasht, Iran · 3: Lincoln University, Jefferson City, Missouri, United States

AUthors' Contributions - A: Study design - B: Data collection - C: Statistical analysis - D: Data interpretation .

E: Manuscript preparation · F: Literature search · G: Funds collection

CORRESPONDING AUTHOR - Reza Shabahang, University of Tehran, 16th Azar Str., Enghelab Square, Tehran, Iran, e-mail: rezashabahang74@gmail.com 


\section{BACKGROUND}

Chronic fatigue syndrome (CFS) affects about one percent of the population worldwide (Lim et al., 2020). It is a poorly understood condition of unexplained, prolonged fatigue that, together with other symptoms (e.g., muscle weakness, pain, anxiety, cognitive impairment), can leave patients bedbound (Carel, Blease, \& Geraghty, 2017). Though there are an increasing number of biological correlates (e.g., immune system abnormalities) associated with the condition, there is still no biologic marker for the disease. Without an objective diagnostic standard, providers rely on self-reported symptoms while ruling out other medical conditions that could explain the symptoms (e.g. thyroid abnormalities, substance abuse; Geraghty et al., 2019). As such, diagnosis and subsequent treatment are largely reliant on patient self-disclosure. Cognitive-behavioral therapy has been a standard treatment for the condition over the past 20 years (Geraghty et al., 2019). Successful cognitive behavioral therapy also relies heavily on self-disclosure. Therefore, chronic fatigue patients' ability to self-disclose illness information is crucial for successful diagnosis and treatment. In addition, self-disclosure is important for building intimacy and social support among those with chronic diseases (Altman \& Taylor, 1973; Terman, Awsumb, Cotler, \& Jason, 2018). This study examines beliefs in sharing illness information among CFS patients.

The Disclosure Processes Model (Chaudoir \& Fisher, 2010) posits that self-disclosure can be complicated for people who have a concealable stigmatized identity. CFS patients often report feeling stigmatized (Green, Romei, \& Natelson, 1999). The vast majority (95\%) feel estranged, and almost half (39\%) report secrecy (Green et al., 1999). Perhaps due to the lack of physiological explanation for the syndrome, the majority of medical personnel believe that the disorder is primarily psychological in nature (Hossenbaccus \& White, 2013). In contrast, patients experiencing physical symptoms perceive the cause of the disorder to be primarily biological (Hossenbaccus \& White, 2013). Well over half (77\%) of patients report having been labelled as "psychological cases” by physicians (Green et al., 1999). These disparate views of providers and patients often lead to patient dissatisfaction with treatment (Carel et al., 2017). Under the circumstances, it is no surprise that many CFS patients feel stigmatized by the medical establishment (Carel et al., 2017). Feeling stigmatized, patients may have a difficult time self-disclosing their illness experiences (Chaudoir \& Fisher, 2010). The resulting communication difficulties can lead to lack of recognition of underlying medical conditions and suboptimal treatment. Increased patient self-disclosure of illness may improve diagnosis and treatment.
While it may be difficult to self-disclose to medical personnel, individuals with chronic fatigue often share their illness experience with those who have similar experiences (Bülow, 2003). Research has supported a range of positive consequences of illness sharing, including an increased sense of control and agency (Hinson \& Sword, 2019; Stahl, 2018). Sharing personal information about illness can be a therapeutic tool in many mental health conditions (see Stratton et al., 2018) and in physical diseases such as cystic fibrosis (Borschuk et al., 2016), fibromyalgia (Wroe \& Bowers, 2019), Huntington's disease (Hakimian, 2000) and HIV (Ssali et al., 2010). Hinson and Sword (2019) demonstrated the importance of sharing illness narratives in gaining a sense of agency over one's health. Ziebland and Wyke (2012) discuss how sharing illness experiences on the Internet can affect individuals' health through increased information access and social support. Though Stahl (2018) warns that sharing illness is risky because individuals may be afraid of being pitied and stigmatized, DasGupta and Charon (2004) consider that illness sharing can be both positive and challenging. Outcomes of illness sharing (e.g., social support or stigmatization) are likely to depend on a variety of process variables including decisions about how, where, and when to share information (Chaudoir \& Fisher, 2010; Omarzu, 2000).

There has been little systematic research on CFS patients' willingness to share illness information. The Beliefs about Sharing Illness Experiences (BASIE) scale (Wroe \& Bowers, 2019) is one of the few existing measures of self-disclosure of illness experiences. The BASIE scale focuses on patients' beliefs about the acceptability of illness experience sharing. Wroe and Bowers (2019) examined beliefs about illness sharing among people with fibromyalgia. Compared to control participants, those with fibromyalgia believed that illness sharing was less acceptable. Moreover, belief in the unacceptability of illness sharing was associated with greater distress. Given the reported similarities between fibromyalgia and chronic fatigue syndrome (Abbi \& Natelson, 2013; Rivera et al., 2013), one might expect to see a similar pattern in CFS patients.

It is reasonable to suppose that some people may be psychologically predisposed to share illness experiences more than others. Interpersonal trust is one psychological characteristic that may influence beliefs about sharing illness experiences. Having interpersonal trust means believing that others are unlikely to behave in ways that could be personally damaging (Gambetta, 1988). According to Social Penetration Theory, intimate relationships develop as people gradually gain trust through progressively more intimate self-disclosure (Altman \& Taylor, 1973). In line with the theory, studies have shown that higher interpersonal trust is associated with 
more consciously intended disclosure and a greater amount of disclosure (Larzelere \& Huston, 1980; Steel, 1991; Wheeless \& Grotz, 1977). Corcoran (1988) showed that client trust in therapists' confidentiality statements is positively associated with client self-disclosure. Furthermore, trust is a predictor of online self-disclosure (Lin, Zhang, Song, \& Omori, 2016; Taddei \& Contena, 2013) Therefore, it seems that interpersonal trust is likely to be associated with illness experience sharing.

Personality variables may also be related to beliefs about sharing illness experiences. The FiveFactor Model (FFM) defines personality along the domains of openness, conscientiousness, extraversion, agreeableness, and neuroticism (see Widiger, 2017). Research indicates that different types of selfdisclosure are associated with the five personality traits (e.g., Caci, Cardaci, \& Miceli, 2019; Chen, Pan, \& Guo, 2016; Chen, Xie, Ping, \& Wang, 2017; Koohikamali, Peak, \& Prybutok, 2017; Loiacono, 2015; Maltseva \& Lutz, 2018). For example, extroversion and openness predict self-disclosure on Facebook (Caci et al., 2019). In this regard, it seems plausible that sharing illness experiences may be influenced by personality traits.

Overall, the present study seeks to investigate the psychometric properties of the Beliefs about Sharing Illness Experiences scale in the chronic fatigue patient population. In addition, we examine the roles of interpersonal trust and personality traits in predicting beliefs about sharing illness experiences. Specific research objectives include establishing the validity and reliability of the BASIE scale in CFS patients. Further, we seek to investigate whether interpersonal trust and personality traits predict beliefs about sharing illness experiences, while narrowing down which aspects of personality predict sharing illness in chronic fatigue patients.

\section{THE PRESENT STUDIES}

Two studies were conducted. Study 1 aimed to evaluate the psychometric properties of the Beliefs about Sharing Illness Experiences scale in CFS patients. Study 2 was conducted to examine the role of interpersonal trust and personality in prediction of the beliefs about sharing illness experiences. In study 1 , the psychometric properties of the $\mathrm{Be}$ liefs about Sharing Illness Experiences scale were evaluated using content validity (CVI and CVR), exploratory factor analysis (EFA), construct validity, Cronbach's $\alpha$, and confirmatory factor analysis (CFA). Study 2 attempted to answer the question of whether interpersonal trust and personality can predict the beliefs about sharing illness using Pearson's correlation coefficient and multiple regression analysis.

\section{PARTICIPANTS AND PROCEDURE}

\section{PARTICIPANTS}

Participants were 283 patients with chronic fatigue syndrome who were referred to Rasht Pain Management Clinic in Rasht City, Iran in 2019. Participants were selected for each study by simple random sampling. Three participants were excluded due to gross errors or not completing surveys. The resulting sample included 140 women and 140 men ( $M$ age 49.30 years, $S D=10.94)$. Sixty percent had a diploma and $40 \%$ had a university degree. The majority $(65.0 \%)$ of participants were married, $12.9 \%$ were single, $22.1 \%$ were divorced. Each study used a separate sample of 140 participants. According to the medical records and results of screening, participants all met the criteria for the clinical diagnosis of chronic fatigue syndrome (Haney et al., 2015; Morris \& Maes, 2013; Sharpe et al., 1991). Ethical principles were practiced in accordance with the World Medical Association Declaration of Helsinki (World Medical Association, 2013). The following measures were printed and handed out with paper/pencils.

\section{MEASURES}

Beliefs about Sharing Illness Experiences scale (BASIE; Wroe \& Bower, 2019). The purpose of the BASIE is to measure patients' beliefs around sharing illness experiences. It is a 19-item instrument with two factors: beliefs about sharing struggles and benefits of sharing illness experiences. The BASIE uses a Likert scale with response choices ranging from 0 (totally disagree) to 100 (totally agree). Thirteen of the items are reverse-scored. The scale yields a summed score with a range from 0 to 1900. Higher scores represent stronger belief in the acceptability of sharing illness experiences. In this study, we used an 11-point Likert scale to help participants discriminate responses more precisely and avoid unnecessary fatigue. The BASIE has shown appropriate psychometric properties (Wroe \& Bowers, 2019). The overall scale $(\alpha=.94)$, beliefs about sharing struggles subscale $(\alpha=.94)$, and benefits of sharing illness experiences $(\alpha=.89)$ show strong internal consistency. Furthermore, the test-retest reliability of the BASIE was satisfactory $(r=.88)$. The correlations between the BASIE and measures of support-seeking and self-sacrifice confirmed appropriate convergent validity of the scale (Wroe \& Bowers, 2019).

Interpersonal Trust Scale (ITS; Rotter, 1967). The 25-item Interpersonal Trust Scale was developed to measure the perception that others can be relied upon not to harm one's interests. The response format is a 5-point scale ranging from 1 (strongly
Beliefs about sharing illness experiences in chronic fatigue syndrome 
Reza Shabahang, Farzin Bagheri Sheykhangafshe, Mara S. Aruguete, Abbas Ali

Hossienkhanzadeh agree) to 5 (strongly disagree). Scores can range from 25 to 125. Rotter (1967) reported appropriate reliability and validity of the questionnaire. Chun and Campbell (1974) also confirmed adequate psychometric attributes of the scale.

NEO-Five Factor Inventory (NEO-FFI; Costa $\&$ McCrae, 1992). The NEO-Five Factor Inventory is 60 -item short form of the NEO Personality InventoryRevised (NEO-PI-R; Costa \& McCrae, 1992). The NEO-FFI measures the five basic personality factors including neuroticism, extraversion, openness to experience, agreeableness, and conscientiousness using 12 items for each factor. The NEO-FFI features a Likert scale with response choices ranging from 1 (strongly disagree) to 5 (strongly agree). Previous studies found appropriate psychometric attributes of the NEO-FFI (Costa \& McCrae, 1992; Egan, Deary, \& Austin, 2000; Robins, Fraley, Roberts, \& Trzesniewski, 2001).

\section{RESULTS}

\section{STUDY 1}

We used the quantitative content validity index (CVI) and content validity ratio (CVR) for measuring content validity of the BASIE scale. The content validity index (CVI) was used based on Waltz and Bausell's content validity index (Waltz \& Bausell, 1981). CVI for the BASIE scale was .91, which is above the minimal required amount of CVI. CVR was determined based on the criterion of Lawshe's table (Lawshe, 1975). The calculated CVR was .92, which is acceptable for 10 professionals.

Exploratory factor analysis (EFA) was used to investigate the factor structure of the BASIE scale. The Kaiser-Meyer-Olkin (KMO) test and Bartlett's test of sphericity were carried out to determine the suitability of data for structure detection. The KMO index was .91 and Bartlett's test for sphericity was significant $\left(\chi^{2}=2668.80, p<.001\right)$, which indicate that factor analysis is appropriate for identifying the model structure. According to the values of KMO and Bartlett's test, principal component analysis (PCA) was used to identify the factor model. PCA of 19 items yielded a two-factor model that accounted for $67.65 \%$ of the variance (Table 1). The first factor, labeled "beliefs about sharing struggles," accounted for $51.77 \%$ of the total variance, and the second factor, labeled "benefits of sharing illness experiences," accounted for $15.88 \%$ of the total variance. Table 1 also indicates the means for each item in the BASIE scale.

For investigation of the internal correlation coefficients between dimensions of the BASIE Scale, Pearson's correlation coefficients were computed. The correlations are outlined in Table 2. All of the correlation coefficients were significant. Positive correlation coefficients suggest that the scale generally measures a specific structure.

The confirmatory factor analysis (CFA) was performed to test the two-factor model of the BASIE scale. The model fit was evaluated using fit indices, including relative $\chi^{2}$, goodness-of-fit index (GFI), adjusted goodness of fit index (AGFI), normed fit index (NFI), Tucker-Lewis index (TLI), comparative fit index (CFI), and root mean square error of approximation (RMSEA) (Mueller, 1999). Findings of CFA confirmed the two-factor model with 19 items.

Table 3 shows goodness-of-fit indices for the twofactor model of the BASIE scale. The CFA results indicated that the data fit the model; RMSEA $=.06$, $\mathrm{CFI}=.97, \mathrm{GFI}=.93$ and adjusted GFI $=.86$. As shown in Table 3, CFA demonstrated a suitable fit to the data.

Cronbach's $\alpha$ coefficients were used to estimate the internal consistency reliability of the BASIE scale. The coefficients obtained for the beliefs about sharing struggles subscale and the benefits of sharing illness experiences subscale were .94 and .93, respectively. The Cronbach's $\alpha$ internal consistency estimate for the overall scale was .94 .

\section{STUDY 2}

Pearson's correlation coefficient and multiple regression analysis were used to examine the question of whether interpersonal trust and personality can predict the beliefs about sharing illness in chronic fatigue patients $(n=140)$. Table 4 reports the descriptive statistics. Table 4 also indicates the correlations between the different variables.

According to the findings (Table 4), interpersonal trust, extraversion, openness to experience, and conscientiousness are correlated with beliefs about sharing illness experiences positively. On the other hand, there is a negative correlation between neuroticism and beliefs about sharing illness experiences. To narrow down the roles of interpersonal trust and personality in prediction of the beliefs about sharing illness experiences, multiple regression analysis was used (Table 5).

Regression analysis showed that interpersonal trust and personality predicted the variance of beliefs about sharing illness experiences. Together, these variables can predict $25.2 \%$ of the variance among criterion variables: $F=6.85, p<.001, R^{2}=.25$. Table 5 shows the regression coefficients and the significance of these coefficients.

According to Table 5 , interpersonal trust $(\beta=.27)$ and extraversion $(\beta=.28)$ predict beliefs about sharing illness experiences positively. In contrast, neuroticism $(\beta=-.26)$ negatively predicts beliefs about sharing illness experiences. 
Table 1

Principle component analysis of items in the BASIE scale $(n=140)$

\begin{tabular}{|c|c|c|c|c|c|}
\hline Item & Factor 1 & Factor 2 & $\mathrm{~h}^{2}$ & M & $S D$ \\
\hline $\begin{array}{l}\text { 1. If people know that I am struggling in any way (physically } \\
\text { or emotionally) with this condition, they will think I am } \\
\text { a weak person. }\end{array}$ & .73 & & .55 & 8.74 & 2.20 \\
\hline $\begin{array}{l}\text { 2. If people know that I am struggling in any way (physically } \\
\text { or emotionally) with this condition, then I am a weak } \\
\text { person. }\end{array}$ & .96 & & .82 & 9.27 & 2.01 \\
\hline $\begin{array}{l}\text { 3. If people know that I am struggling in any way (physically } \\
\text { or emotionally) with this condition, then I have failed in } \\
\text { some way. }\end{array}$ & .79 & & .66 & 9.18 & 1.82 \\
\hline $\begin{array}{l}\text { 4. If people know that I am struggling in any way (physically } \\
\text { or emotionally) with this condition, they will think I have } \\
\text { failed in some way. }\end{array}$ & .74 & & .60 & 9.02 & 1.90 \\
\hline 5. If I ask for help, then I am letting people down. & .89 & & .64 & 9.25 & 2.21 \\
\hline $\begin{array}{l}\text { 6. If I have difficulties with this condition, I should not admit } \\
\text { it to others. }\end{array}$ & .69 & & .46 & 9.01 & 2.17 \\
\hline $\begin{array}{l}\text { 7. It is shameful to be struggling in any way (physically or } \\
\text { emotionally) with this condition. }\end{array}$ & .84 & & .65 & 9.67 & 1.70 \\
\hline $\begin{array}{l}\text { 8. Experiencing symptoms of this condition in front of others } \\
\text { is embarrassing. }\end{array}$ & .86 & & .70 & 9.25 & 1.98 \\
\hline $\begin{array}{l}\text { 9. If people know about this condition, they will treat me like } \\
\text { a different person. }\end{array}$ & .56 & & .65 & 9.02 & 2.03 \\
\hline $\begin{array}{l}\text { 10. I should keep this condition a secret from most people } \\
\text { I know. }\end{array}$ & .64 & & .52 & 9.04 & 2.37 \\
\hline $\begin{array}{l}\text { 11. People will not want to be friends with me if they know } \\
\text { I have difficulties with my condition. }\end{array}$ & .84 & & .67 & 9.04 & 2.00 \\
\hline $\begin{array}{l}\text { 12. To be acceptable to others, I should keep my condition } \\
\text { mainly to myself. }\end{array}$ & .92 & & .80 & 8.77 & 2.68 \\
\hline $\begin{array}{l}\text { 13. Others will expect me to manage this condition without } \\
\text { support from them. }\end{array}$ & .55 & & .53 & 7.80 & 3.46 \\
\hline 14. If I tell people about my condition, they will support me. & & .80 & .70 & 6.73 & 3.07 \\
\hline $\begin{array}{l}\text { 15. If people know about my condition, they will still treat me } \\
\text { like "me". }\end{array}$ & & .85 & .82 & 7.07 & 2.91 \\
\hline $\begin{array}{l}\text { 16. It would be helpful for people to know about my condition } \\
\text { as they will understand some of the things I have to do } \\
\text { because of my condition. }\end{array}$ & & .95 & .81 & 7.02 & 3.12 \\
\hline 17. People will not judge me for having this condition. & & .87 & .77 & 6.76 & 3.02 \\
\hline $\begin{array}{l}\text { 18. If I talk to people about my condition, they will feel pleased } \\
\text { that I have shared this with them. }\end{array}$ & & .89 & .75 & 6.88 & 3.09 \\
\hline $\begin{array}{l}\text { 19. Telling friends about my condition would strengthen our } \\
\text { friendship. }\end{array}$ & & .95 & .77 & 6.91 & 3.14 \\
\hline$\%$ of variance & 51.77 & 15.88 & & & \\
\hline$\alpha$ & .94 & .93 & & & \\
\hline
\end{tabular}


Table 2

Correlation matrix of the BASIE scale dimensions $(n=140)$

\begin{tabular}{lcc}
\hline Dimension & Beliefs about sharing struggles & Benefits of sharing illness \\
\hline Beliefs about sharing struggles & $.52^{* *}$ & $.52^{* *}$ \\
Benefits of sharing illness & & \\
\hline Note. ${ }^{* *} p<.01$. &
\end{tabular}

Reza Shabahang,

Farzin Bagheri Sheykhangafshe, Mara S. Aruguete, Abbas Ali Hossienkhanzadeh

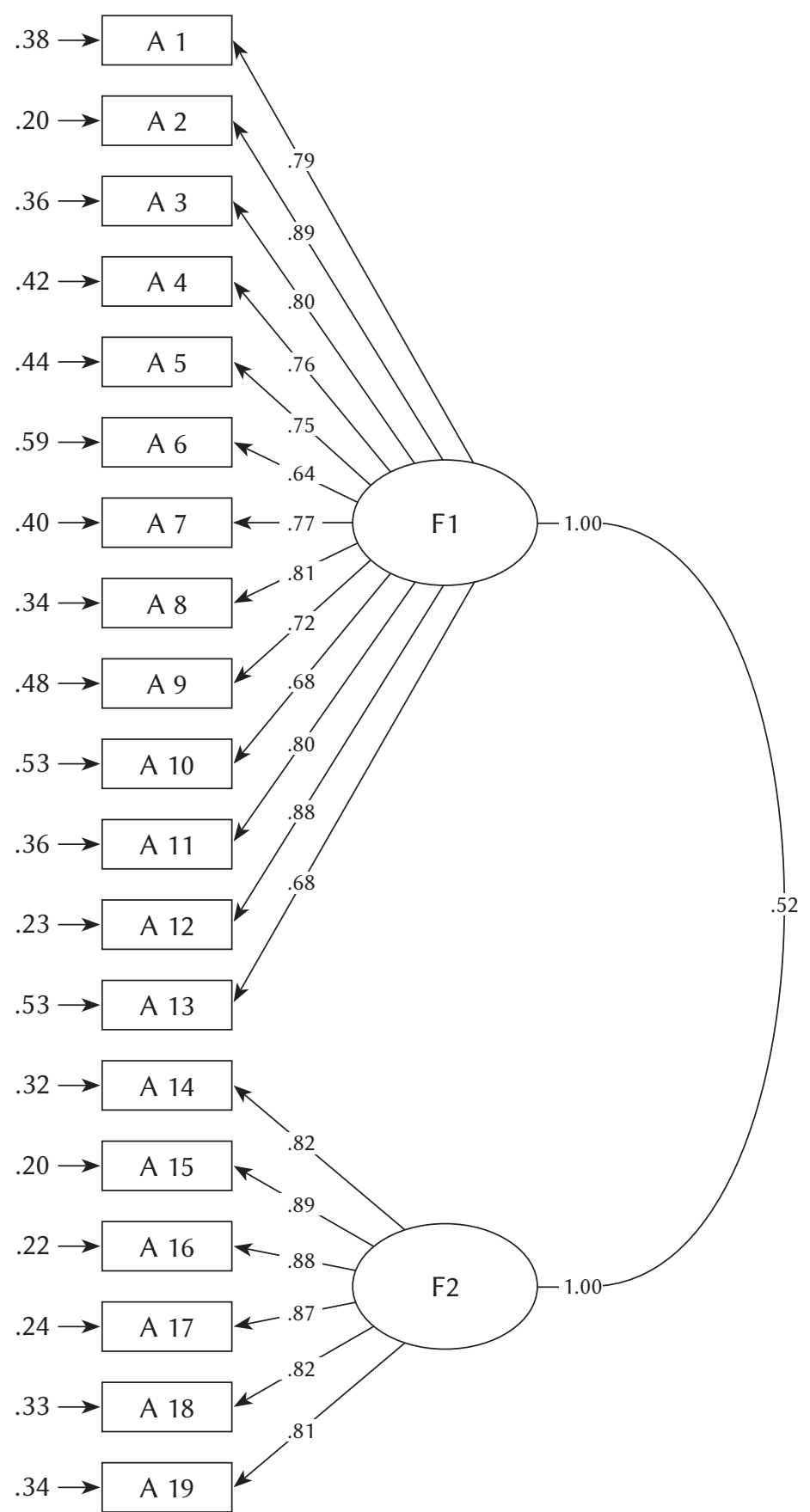

Note. F1 - beliefs about sharing struggles, F2 - benefits of sharing illness experiences.

Figure 1. The two-factor model of the BASIE scale. 
Table 3

Goodness-of-fit indices for the two-factor model of the BASIE scale $(n=70)$

\begin{tabular}{lc}
\hline Modification indices & Tested model \\
\hline$\chi^{2}$ & 390.02 \\
$d f$ & 151 \\
$p$ & $<.001$ \\
$\chi^{2} / d f$ & 2.59 \\
Goodness of fit index (GFI) & .93 \\
Adjusted goodness of fit index (AGFI) & .86 \\
Normed fit index (NFI) & .96 \\
Tucker-Lewis index (TLI) & .97 \\
Comparative fit index (CFI) & .97 \\
Root mean square error of approximation (RMSEA) & .06 \\
\hline
\end{tabular}

Table 4

Descriptive indices and correlation coefficients of the study variables $(n=140)$

\begin{tabular}{|c|c|c|c|c|c|c|c|c|c|}
\hline Variable & M & $S D$ & 1 & 2 & 3 & 4 & 5 & 6 & 7 \\
\hline 1. Interpersonal trust & 77.62 & 8.25 & 1 & & & & & & \\
\hline 2. Neuroticism & 33.79 & 4.52 & .13 & 1 & & & & & \\
\hline 3. Extraversion & 34.19 & 4.98 & $.51^{* *}$ & $.21^{*}$ & 1 & & & & \\
\hline 4. Openness to experience & 36.40 & 4.24 & $.25^{* *}$ & $.37^{* *}$ & $.54^{* *}$ & 1 & & & \\
\hline 5. Agreeableness & 36.53 & 4.35 & $.41^{* *}$ & $.43^{* *}$ & $.52^{* *}$ & $.53^{* *}$ & 1 & & \\
\hline 6. Conscientiousness & 37.26 & 4.64 & $.47^{* *}$ & $.31^{* *}$ & $.73^{* *}$ & $.60^{* *}$ & $.67^{* *}$ & 1 & \\
\hline $\begin{array}{l}\text { 7. Beliefs about sharing } \\
\text { illness experiences }\end{array}$ & 147.28 & 21.06 & $.37^{* *}$ & $-.17^{*}$ & $.39^{* *}$ & $.23^{* *}$ & .09 & $.27^{* *}$ & 1 \\
\hline
\end{tabular}

Table 5

Regression coefficients of beliefs about sharing illness experiences based on interpersonal trust and personality

\begin{tabular}{lrcrrr}
\hline Predictive variables & $B$ & Standard error & $\beta$ & $t$ & $p$ \\
\hline Constant & 87.90 & 19.01 & & 4.62 & \multicolumn{1}{c}{001} \\
Interpersonal trust & 0.68 & 0.22 & .27 & 3.01 & .003 \\
Neuroticism & -1.22 & 0.38 & -.26 & -3.14 & .002 \\
Extraversion & 1.20 & 0.48 & .28 & 2.49 & .014 \\
Openness to experience & 0.91 & 0.49 & .18 & 1.87 & .064 \\
Agreeableness & -0.83 & 0.52 & -.17 & -1.61 & .110 \\
Conscientiousness & 0.11 & 0.58 & .02 & 0.19 & .849 \\
\hline
\end{tabular}

\section{DISCUSSION}

The present study aimed to investigate beliefs about sharing illness experiences in individuals with chronic fatigue syndrome (CFS). Because of the uncertainty regarding biological causes of CFS, patients commonly feel stigma that their physical symptoms are not recognized as legitimate, or that the syndrome is a purely psychological problem (Green et al., 1999). Patients with CFS experience a particularly poor quality of life, worse than most chronic diseases including cancer (Lim et al., 2020). Perceived
Beliefs about sharing illness experiences in chronic fatigue syndrome 
Reza Shabahang,

Farzin Bagheri Sheykhangafshe, Mara S. Aruguete, Abbas Ali Hossienkhanzadeh stigma may inhibit patients from sharing illness experiences with medical personnel, mental health staff, and others. However, sharing illness experiences may be crucial for diagnosis, proper treatment, and securing social support. Moreover, research has documented many positive consequences of illness experience sharing including an increased sense of personal control (Hinson \& Sword, 2019; Stahl, 2018). Indeed, self-disclosure is a prominent coping mechanism in individuals struggling with chronic fatigue syndrome (Green et al., 1999; Terman et al., 2018), and level of social support predicts positive health and mental health outcomes in CFS patients (Jason, Witter, \& Torres-Harding, 2003). There is evidence to indicate that storytelling in humans tends to be associated with increased cooperation and other evolutionary benefits (Smith et al., 2017). Thorough examination of illness sharing in CFS patients is needed to investigate ways to maximize the benefits of selfdisclosure.

Study 1 was conducted to examine the psychometric properties of the Beliefs about Sharing Illness Experiences scale in CFS patients. In line with Wroe and Bowers' study (2019), exploratory factor analysis and confirmatory factor analysis confirmed the two-factor model with 19 items. Positive correlation coefficients between two subscales of the BASIE scale also suggest that the scale generally measures a specific structure. In addition, Cronbach's $\alpha$ indicate good internal consistency reliability of the BASIE scale. The strong psychometric properties of the scale make it a good candidate for further examining the barriers to illness sharing in patients with CFS and related syndromes. Future research might use the scale to examine the demographic, psychological, and social correlates of beliefs about illness sharing.

In Study 2, we examined whether interpersonal trust and personality could predict beliefs about sharing illness experiences. Our findings support previous research showing that trust is an important factor in illness experience sharing (Kaushansky et al., 2017). Patients with higher levels of interpersonal trust have more positive beliefs about sharing illness experiences and do not think that illness sharing is shameful. On the other hand, lower levels of interpersonal trust result in negative beliefs about sharing illness experiences. As predicted by social penetration theory (Altman \& Taylor, 1973), those with higher levels of interpersonal trust might find it easier to self-disclose, and this gradual self-disclosure builds relationship intimacy. In addition to increasing communication and social support, intimacy may reduce the sense of estrangement that many chronic fatigue patients experience (Green et al., 1999).

We also found that personality was related to beliefs about sharing illness experiences. Specifically, extraversion positively predicted beliefs about sharing illness experiences. In contrast, neuroticism neg- atively predicted beliefs about sharing illness experiences. Extraverted CFS patients may be more likely to engage with the world actively by talking about their illness journeys. Self-confidence and sociability may help them to share their illness experiences without fear of abuse. By contrast, chronic fatigue syndrome patients with higher neuroticism may be afraid of the negative consequences of illness sharing. Future research should examine ways to increase safe self-disclosure among patients high in neuroticism in order to minimize the negative effects of being reluctant to share illness experiences.

Beliefs about sharing illness experiences have several implications for chronic fatigue patients. According to the Disclosure Processes Model (Chaudoir \& Fisher, 2010), self-disclosure among stigmatized groups like those with CFS may be complicated insofar as disclosing personal information might result in the target of the disclosure expressing greater acceptance and support or greater rejection and estrangement. The benefits of greater wellbeing of patients largely depends on the outcome. That said, there are a range of antecedents to self-disclosure including decisions about when and how to disclose, the best ways to communicate effectively, and how to cope with the outcomes of disclosure (Chaudoir \& Fisher, 2010; Omarzu, 2000). The outcomes of disclosure can be influenced by any of these factors, giving patients some control. Psychoeducational interventions that emphasize methods of self-disclosure aimed at maximizing beneficial outcomes may increase safe selfdisclosure in stigmatized groups. Further research should examine the efficacy of such interventions.

This study has some limitations. The data were self-reported, correlational and cross-sectional. The data collection took place in Iran. There are few published studies on CFS in Iran, and the extent to which the results can be generalized to other cultures is unclear. Moreover, factors such as education level, comorbid conditions, stress, and social status were not measured. These factors should be taken into account in future studies.

\section{ACKNOWLEDGEMENTS}

The authors would like to express their sincere gratitude to Dr. Abigail Wroe. The authors appreciate all the participating volunteers and organizations involved in the implementation of this research.

\section{ETHICAL STATEMENT}

All ethical considerations such as personal satisfaction, data retention and destruction, and informed participation were taken into account in accordance with the Declaration of Helsinki. 


\section{REFERENCES}

Abbi, B., \& Natelson, B. H. (2013). Is chronic fatigue syndrome the same illness as fibromyalgia: Evaluating the 'single syndrome' hypothesis. QJM: An International Journal of Medicine, 106, 3-9. https:// doi.org/10.1093/qjmed/hcs156

Altman, I., \& Taylor, D. A. (1973). Social penetration: The development of interpersonal relationships. New York: Holt, Rinehart, \& Winston.

Borschuk, A., Everhart, R. S., Eakin, M. N., RandGiovannetti, D., Borrelli, B., \& Riekert, K. A. (2016). Disease disclosure in individuals with cystic fibrosis: Association with psychosocial and health outcomes. Journal of Cystic Fibrosis, 15, 696-702. https://doi.org/10.1016/j.jcf.2016.02.011

Bülow, P. H. (2003). Making sense of contested illness: Talk and narratives about chronic fatigue (Doctoral dissertation). Linköping: Linköping University.

Caci, B., Cardaci, M., \& Miceli, S. (2019). Development and maintenance of self-disclosure on Facebook: The role of personality traits. SAGE Open, 9, 1-14. https://doi.org/10.1177/2158244019856948

Carel, H., Blease, C., \& Geraghty, K. (2017). Epistemic injustice in healthcare encounters: Evidence from chronic fatigue syndrome. Journal of Medical Ethics, 43, 549-557. https://doi.org/10.1136/medethics-2016-103691

Chaudoir, S. R., \& Fisher, J. D. (2010). The disclosure processes model: understanding disclosure decision making and postdisclosure outcomes among people living with a concealable stigmatized identity. Psychological Bulletin, 136, 236-256. https:// doi.org/10.1037/a0018193

Chen, X., Pan, Y., \& Guo, B. (2016). The influence of personality traits and social networks on the self-disclosure behavior of social network site users. Internet Research, 26, 566-586. https://doi.org/ 10.1108/IntR-05-2014-0145

Chen, W., Xie, X., Ping, F., \& Wang, M. (2017). Personality differences in online and offline self-disclosure preference among adolescents: a person-oriented approach. Personality and Individual Differences, 105, 175-178. https://doi.org/10.1016/j.paid.2016.09.048

Chun, K., \& Campbell, J. B. (1974). Dimensionality of the Rotter Interpersonal Trust Scale. Psychological Reports, 35, 1059-1070. https://doi.org/10.2466/ pr0.1974.35.3.1059

Corcoran, K. J. (1988). The relationship of interpersonal trust to self-disclosure when confidentiality is assured. The Journal of Psychology, 122, 193-195. https://doi.org/10.1080/00223980.1988.9712705

Costa, P. T., \& McCrae, R. R. (1992). Revised NEO Personality Inventory (NEO PI-R) and NEO Five-Factor Inventory (NEO-FFI) professional manual. Lutz, FL: Psychological Assessment Resources, Inc.

DasGupta, S., \& Charon, R. (2004). Personal illness narratives: Using reflective writing to teach em- pathy. Academic Medicine, 79, 351-356. https:// doi.org/10.1097/00001888-200404000-00013

Egan, V., Deary, I., \& Austin, E. (2000). The NEO-FFI: Emerging British norms and an item-level analysis suggest $\mathrm{N}, \mathrm{A}$, and $\mathrm{C}$ are more reliable than $\mathrm{O}$ and $\mathrm{E}$. Personality and Individual Differences, 29, 907-920. https://doi.org/10.1016/S0191-8869(99)00242-1

Gambetta, D. (1988) Can we trust trust? In D. Gambetta (Ed.), Trust: Making and breaking cooperative relations (pp. 213-237). New York: Blackwell.

Geraghty, K., Jason, L., Sunnquist, M., Tuller, D., Blease, C., \& Adeniji, C. (2019). The 'cognitive behavioural model' of chronic fatigue syndrome: Critique of a flawed model. Health Psychology Open, 6, 1-14. https://doi.org/10.1177/2055102919838907

Green, J., Romei, J., \& Natelson, B. H. (1999). Stigma and chronic fatigue syndrome. Journal of Chronic Fatigue Syndrome, 5, 63-75. https://doi.org/10.1300/ J092v05n02_04

Hakimian, R. (2000). Disclosure of Huntington's disease to family members: the dilemma of known but unknowing parties. Genetic Testing, 4, 359-364. https://doi.org/10.1089/109065700750065090

Haney, E., Smith, M. E., McDonagh, M., Pappas, M., Daeges, M., Wasson, N., \& Nelson, H. D. (2015). Diagnostic methods for myalgic encephalomyelitis/chronic fatigue syndrome: a systematic review for a national institutes of health pathways to prevention workshop. Annals of Internal Medicine, 162, 834-840. https://doi.org/10.7326/M15-0443

Hinson, K., \& Sword, B. (2019). Illness narratives and Facebook: Living illness well. Humanities, 8, 106. https://doi.org/10.3390/h8020106

Hossenbaccus, Z., \& White, P. D. (2013). Views on the nature of chronic fatigue syndrome: Content analysis. JRSM Short Reports, 4, 1-6. https://doi. org/10.1258/shorts.2012.012051

Jason, L., Witter, E., \& Torres-Harding, S. (2003). Chronic fatigue syndrome, coping, optimism and social support. Journal of Mental Health, 12, 109118. https://doi.org/10.1080/09638230021000058346

Kaushansky, D., Cox, J., Dodson, C., McNeeley, M., Kumar, S., \& Iverson, E. (2017). Living a secret: Disclosure among adolescents and young adults with chronic illnesses. Chronic Illness, 13, 49-61. https:// doi.org/10.1177/1742395316655855

Koohikamali, M., Peak, D. A., \& Prybutok, V. R. (2017). Beyond self-disclosure: Disclosure of information about others in social network sites. Computers in Human Behavior, 69, 29-42. https://doi. org/10.1016/j.chb.2016.12.012

Larzelere, R. E., \& Huston, T. L. (1980). The Dyadic Trust Scale: Toward understanding interpersonal trust in close relationships. Journal of Marriage and Family, 42, 595-604. https://doi.org/10.2307/351903

Lawshe, C. H. (1975). A quantitative approach to content validity. Personnel Psychology, 28, 563-575. https://doi.org/10.1111/j.1744-6570.1975.tb01393.x
Beliefs about sharing illness experiences in chronic fatigue syndrome 
Reza Shabahang,

Farzin Bagheri Sheykhangafshe, Mara S. Aruguete, Abbas Ali

Hossienkhanzadeh
Lin, W., Zhang, X., Song, H., \& Omori, K. (2016). Health information seeking in the Web 2.0 age: Trust in social media, uncertainty reduction, and self-disclosure. Computers in Human Behavior, 56, 289-294. https://doi.org/10.1016/j.chb.2015.11.055

Lim, E., Ahn, Y., Jang, E., Lee, S., Lee, S., \& Son, C. (2020). Systematic review and meta-analysis of the prevalence of chronic fatigue syndrome/myalgic encephalomyelitis (CFS/ME). Journal of Translational Medicine, 18, 100. https://doi.org/10.1186/ s12967-020-02269-0

Loiacono, E. T. (2015). Self-disclosure behavior on social networking web sites. International Journal of Electronic Commerce, 19, 66-94. https://doi.org/10. 1080/10864415.2015.979479

Maltseva, K., \& Lutz, C. (2018). A quantum of self: a study of self-quantification and self-disclosure. Computer in Human Behavior, 81, 102-114. https:// doi.org/10.1016/j.chb.2017.12.006

Morris, G., \& Maes, M. (2013). Case definitions and diagnostic criteria for myalgic encephalomyelitis and chronic fatigue syndrome: From clinical-consensus to evidence-based case definitions. Neuro Endocrinology Letters, 34, 185-199.

Mueller, R. O. (1999). Basic principles of structural equation modeling: an introduction to LISREL and EQS. Berlin: Springer Science \& Business Media.

Omarzu, J. A. (2000). Disclosure decision model: Determining how and when individuals will self-disclose. Personality and Social Psychology Review, 4, 174-185. https://doi.org/10.1207/S15327957PSPR0402_05

Rivera, J., Collado, A., Alegre, J., Blanch, J., Vidal, J., Arias, A., \& Carbonel, J. (2013). Similarities between fibromyalgia and chronic fatigue syndrome: a single disease? Annals of the Rheumatic Diseases, 71, 272. https://doi.org/10.1136/annrheumdis-2012eular.2310

Robins, R. W., Fraley, R. C., Roberts, B. W., \& Trzesniewski, K. H. (2001). A longitudinal study of personality change in young adulthood. Journal of Personality, 69, 617-640. https://doi.org/10.1111/1467-6494.694157

Rotter, J. B. (1967). A new scale for the measurement of interpersonal trust. Journal of Personality, 35, 651-665. https://doi.org/10.1111/j.1467-6494.1967. tb01454.x

Sharpe, M. C., Archard, L. C., Banatvala, J. E., Borysiewicz, L. K., Clare, A. W., David, A., Edwards, R. H., Hawton, K. E., Lambert, H. P., \& Lane, R. J. (1991). Chronic fatigue syndrome: Guidelines for research. Journal of the Royal Society of Medicine, 84, 118-121.

Smith, D., Schlaepfer, P., Major, K., Dyble, M., Page, A. E., Thompson, J., Chaudhary, N., Salali, G. D., Mace, R., Astete, L., Ngales, M., Vinicius, L., \& Bamberg Migliano, A. (2017). Cooperation and the evolution of hunter-gatherer storytelling. Nature Communications, 8, 1853. https://doi.org/10. 1038/s41467-017-02036-8
Ssali, S., Atuyambe, L., Tumwine, C., Seguijja, E., Nekesa, N., Nannungi, A., Ryan, G., \& Wagner, G. (2010). Reasons for disclosure of HIV status by people living with HIV/AIDS and in HIV care in Uganda: an exploratory study. AIDS Patient Care and STDs, 24, 675-681. https://doi.org/10.1089/apc.2010.0062

Stahl, D. (2018). Imaging and imagining illness: Becoming whole in a broken body. Eugene, OR: Cascade Books.

Steel, J. L. (1991). Interpersonal correlates of trust and self-disclosure. Psychological Reports, 68, 13191320. https://doi.org/10.2466/pr0.1991.68.3c.1319

Stratton, E., Einboden, R., Ryan, R., Choi, I., Harvey, S. B., \& Glozier, N. (2018). Deciding to disclose a mental health condition in male-dominated workplaces: a focus-group study. Frontiers in Psychiatry, 9, 684. https://doi.org/10.3389/fpsyt.2018.00684

Taddei, S., \& Contena, B. (2013). Privacy, trust and control: Which relationships with online self-disclosure? Computers in Human Behavior, 29, 821826. https://doi.org/10.1016/j.chb.2012.11.022

Terman, J. M., Awsumb, J. M., Cotler, J., \& Jason, L. A. (2018). Confirmatory factor analysis of a myalgic encephalomyelitis and chronic fatigue syndrome stigma scale. Journal of Health Psychology, online ahead of print. https://doi.org/10.1177/1359105318796906

Waltz, C. F., \& Bausell, R. B. (1981). Nursing research: Design, statistics, and computer analysis. Philadelphia, PA: F.A. Davis Co.

Wheeless, L. R., \& Grotz, J. (1977). The measurement of trust and its relationship to self-disclosure. $\mathrm{Hu}$ man Communication Research, 3, 250-257. https:// doi.org/10.1111/j.1468-2958.1977.tb00523.x

Widiger, T. A. (Ed). (2017). The Oxford handbook of the Five-Factor Model. New York: Oxford University Press.

World Medical Association (2013). World Medical Association Declaration of Helsinki: Ethical principles for medical research involving human subjects. JAMA, 310, 2191-2194. https://doi.org/10.1001/jama. 2013.281053

Wroe, A. L., \& Bowers, H. M. (2019). Beliefs about sharing illness experiences: Development of a scale and relationship with symptoms of fibromyalgia. British Journal of Health Psychology, 24, 687-703. https://doi.org/10.1111/bjhp.12376

Ziebland, S., \& Wyke, S. (2012). Health and illness in a connected world: How might sharing experiences on the internet affect people's health? The Milbank Quarterly, 90, 219-249. https://doi. org/10.1111/j.1468-0009.2012.00662.x 